\title{
QUANTIFICATION OF ENDOTHELIAL alpha(V)beta(3) EXPRESSION WITH HIGH-FREQUENCY ULTRASOUND AND TARGETED MICROBUBBLES: IN VITRO AND IN VIVO STUDIES
}

Citation for published version (APA):

Daeichin, V., Kooiman, K., Skachkov, I., Bosch, J. G., Theelen, T. L., Steiger, K., Needles, A., Janssen, B. J., Daemen, M. J. A. P., van der Steen, A. F. W., de Jong, N., \& Sluimer, J. C. (2016). QUANTIFICATION OF ENDOTHELIAL alpha(V)beta(3) EXPRESSION WITH HIGH-FREQUENCY ULTRASOUND AND TARGETED MICROBUBBLES: IN VITRO AND IN VIVO STUDIES. Ultrasound in Medicine and Biology, 42(9), 2283-2293. https://doi.org/10.1016/j.ultrasmedbio.2016.05.005

Document status and date:

Published: 01/09/2016

DOI:

10.1016/j.ultrasmedbio.2016.05.005

Document Version:

Publisher's PDF, also known as Version of record

\section{Document license:}

Taverne

\section{Please check the document version of this publication:}

- A submitted manuscript is the version of the article upon submission and before peer-review. There can be important differences between the submitted version and the official published version of record. People interested in the research are advised to contact the author for the final version of the publication, or visit the DOI to the publisher's website.

- The final author version and the galley proof are versions of the publication after peer review.

- The final published version features the final layout of the paper including the volume, issue and page numbers.

Link to publication

\footnotetext{
General rights rights.

- You may freely distribute the URL identifying the publication in the public portal. please follow below link for the End User Agreement:

www.umlib.nl/taverne-license

Take down policy

If you believe that this document breaches copyright please contact us at:

repository@maastrichtuniversity.nl

providing details and we will investigate your claim.
}

Copyright and moral rights for the publications made accessible in the public portal are retained by the authors and/or other copyright owners and it is a condition of accessing publications that users recognise and abide by the legal requirements associated with these

- Users may download and print one copy of any publication from the public portal for the purpose of private study or research.

- You may not further distribute the material or use it for any profit-making activity or commercial gain

If the publication is distributed under the terms of Article 25fa of the Dutch Copyright Act, indicated by the "Taverne" license above,

Download date: 26 Apr. 2023 

Copyright (C) 2016 World Federation for Ultrasound in Medicine \& Biology Printed in the USA. All rights reserved $0301-5629 / \$$ - see front matter

\title{
QUANTIFICATION OF ENDOTHELIAL $\alpha_{\mathrm{V}} \beta_{3}$ EXPRESSION WITH HIGH-FREQUENCY ULTRASOUND AND TARGETED MICROBUBBLES: IN VITRO AND IN VIVO STUDIES
}

\author{
Verya Daeichin, ${ }^{*}$ Klazina Kooiman, ${ }^{*}$ Ilya Skachkov, ${ }^{*}$ Johan G. Bosch, ${ }^{*}$ Thomas L. Theelen ${ }^{\dagger}$ \\ Katja Steiger, ${ }^{\ddagger}$ Andrew Needles,${ }^{\S}$ Ben J. Janssen, ${ }^{\Uparrow}$ Mat J. A. P. Daemen, \\ Antonius F. W. van der Steen, *\#** Nico DE Jong, ${ }^{*}{ }^{* \dagger}$ and Judith C. Sluimer \\ * Biomedical Engineering, Thorax Center, Erasmus MC, Rotterdam, The Netherlands; ${ }^{\dagger}$ Department of Pathology, Maastricht \\ University Medical Center, Maastricht, The Netherlands; ${ }^{\ddagger}$ Institute of Pathology, Technical University of Munich, Munich, \\ Germany; ${ }^{\$}$ VisualSonics Inc., Toronto, Ontario, Canada; ${ }^{\top}$ Department of Pharmacology, MUMC, Maastricht, The Netherlands; \\ "Department of Pathology, Academic Medical Center, Amsterdam, The Netherlands; ${ }^{\#}$ Laboratory of Acoustical Wavefield \\ Imaging, Faculty of Applied Sciences, Delft University of Technology, Delft, The Netherlands; ** Shenzhen Institute of \\ Advanced Technologies, Shenzhen, China; and ${ }^{\dagger \dagger}$ Netherlands Heart Institute, Utrecht, The Netherlands
}

$$
\text { (Received } 7 \text { January 2016; revised } 3 \text { May 2016; in final form } 4 \text { May 2016) }
$$

\begin{abstract}
Angiogenesis is a critical feature of plaque development in atherosclerosis and might play a key role in both the initiation and later rupture of plaques. The precursory molecular or cellular pro-angiogenic events that initiate plaque growth and that ultimately contribute to plaque instability, however, cannot be detected directly with any current diagnostic modality. This study was designed to investigate the feasibility of ultrasound molecular imaging of endothelial $\alpha_{\mathrm{v}} \beta_{3}$ expression in vitro and in vivo using $\alpha_{\mathrm{v}} \beta_{3}$-targeted ultrasound contrast agents (UCAs). In the in vitro study, $\alpha_{\mathrm{v}} \beta_{3}$ expression was confirmed by immunofluorescence in a murine endothelial cell line and detected using the targeted UCA and ultrasound imaging at 18-MHz transmit frequency. In the in vivo study, expression of endothelial $\alpha_{\mathrm{v}} \beta_{3}$ integrin in murine carotid artery vessels and microvessels of the salivary gland was quantified using targeted UCA and high-frequency ultrasound in seven animals. Our results indicated that endothelial $\alpha_{\mathrm{v}} \beta_{3}$ expression was significantly higher in the carotid arterial wall containing atherosclerotic lesions than in arterial segments without any lesions. We also found that the salivary gland can be used as an internal positive control for successful binding of targeted UCA to $\alpha_{\mathrm{v}} \beta_{3}$ integrin. In conclusion, $\alpha_{\mathrm{v}} \beta_{3}$-targeted UCA allows noninvasive assessment of the expression levels of $\alpha_{\mathrm{v}} \beta_{3}$ on the vascular endothelium and may provide potential insights into early atherosclerotic plaque detection and treatment monitoring. (E-mail: v.daeichin@erasmusmc.nl or http://www.erasmusmc.nl/thoraxcenterbme/) (c) 2016 World Federation for Ultrasound in Medicine \& Biology.
\end{abstract}

Key Words: Molecular imaging, Targeted microbubble, $\alpha_{\mathrm{v}} \beta_{3}$ integrin, High-frequency ultrasound, Murine atherosclerosis, Endothelial cell, In vitro, In vivo.

\section{INTRODUCTION}

Ultrasound molecular imaging features high sensitivity, availability, rapid execution of imaging protocols and relatively low cost (Kaufmann and Lindner 2007; van Rooij et al. 2015), and its potential for imaging biological processes at the molecular level has been illustrated. The key element of this technique compared with regular diagnostic ultrasound imaging is the use of ultrasound contrast agents (UCAs) decorated with binding ligands

Address correspondence to: Verya Daeichin, Thoraxcenter Biomedical Engineering, Room Ee23.02, Erasmus MC, PO Box 2040, 3000 CA Rotterdam, The Netherlands. E-mail: v.daeichin@erasmusmc.nl or http://www.erasmusmc.nl/thoraxcenterbme/ such as antibodies and small peptides. These functionalized UCAs, so-called targeted UCAs (tUCAs) or targeted microbubbles, can bind to biomarkers involved in various disease processes. As UCAs are blood pool agents (Greis 2009), tUCAs can only bind to intravascular biomarkers on intravenous administration. Combined with dedicated ultrasound imaging sequences and the latest transducer technology, ultrasound molecular imaging allows quantitative assessment of molecular target expression with high sensitivity. The aforementioned features of this technique have opened new diagnostic applications, including the detection of atherosclerosis (Kaufmann 2009; Khanicheh et al. 2013a, 2013b; Liu et al. 2013; Shim et al. 2015), thrombosis (Alonso et al. 2007), 
neovasculature (Deshpande et al. 2011; Leong-Poi et al. 2003; Shelton et al. 2016; Stieger et al. 2008; Streeter et al. 2013), lymph nodes (Hauff et al. 2004) and inflammation (Bettinger et al. 2012; Davidson et al. 2014; Lindner 2010; ten Kate et al. 2010). It also provides helpful insights into the genesis, progress and prevention of diseases (Dayton and Ferrara 2002; Khanicheh et al. 2013a; Klibanov 2006; Lanza et al. 1996; Lindner 2004; Liu et al. 2013; Palmowski et al. 2008; Shim et al. 2015; Streeter et al. 2013; van Rooij et al. 2015).

Atherosclerosis is characterized by accumulation of lipids, inflammatory cells and connective tissue within the arterial wall. A number of pathophysiologic mechanisms are thought to be involved in the progression of an atherosclerotic lesion into a vulnerable plaque (Naghavi et al. 2003). Intraplaque neovascularization and adventitial vasa vasorum have gained interest as a preceding or associated factor in the development, progression and instability of atherosclerotic plaques (Barger et al. 1984; Hellings et al. 2010; Langheinrich et al. 2007; Michel et al. 2011; Moreno et al. 2006; Sluimer et al. 2008). The presence of intraplaque neovascularization has been identified as an independent predictor of intraplaque hemorrhage and plaque rupture (Moreno et al. 2004; Purushothaman et al. 2003). Intraplaque neovascularization is therefore increasingly investigated as a marker for the non-invasive identification of vulnerable plaques. It has been reported that angiogenic activity in the atherosclerotic plaques coincides with $\alpha_{\mathrm{v}} \beta_{3}$-integrin by the adventitial vasa vasorum and intraplaque neovascularization (Brooks et al. 1994; Haubner 2006; Hoshiga et al. 1995; Hynes 1987). Therefore, $\alpha_{\mathrm{v}} \beta_{3}$ integrin is an appropriate biomarker for targeted ultrasound imaging of intraplaque neovascularization and adventitial vasa vasorum, whereas adhesion of tUCAs to endothelial cells provides the signal enhancement. This molecular marker has been used for ultrasound molecular imaging of angiogenesis in tumors and hindlimb ischemia (Ellegala 2003; Leong-Poi et al. 2003). Although $\alpha_{\mathrm{v}} \beta_{3}$ integrin expression in atherosclerotic plaques has been quantified ex vivo using near-infrared optical imaging in mice (Tedesco et al. 2009) and in vivo with magnetic resonance imaging in rabbits (Winter et al. 2003) and positron emission tomography in mice (Laitinen et al. 2009), to the best of our knowledge, no in vivo ultrasound molecular imaging of adventitial vasa vasorum and/or intraplaque neovascularization with $\alpha_{\mathrm{v}} \beta_{3}$ integrin has been reported.

Here, we provide in vitro and in vivo proof-ofconcept for molecular imaging of $\alpha_{\mathrm{v}} \beta_{3}$ in carotid artery lesions in apolipoprotein E-deficient $\left(\mathrm{ApoE}^{-/-}\right)$mice with proven expansion of adventitial vasa vasorum (Rademakers et al. 2013). We hypothesized that molecular imaging of $\alpha_{\mathrm{v}} \beta_{3}$-integrin with tUCA could be used to quantify the adventitial vasa vasorum underlying atherosclerosis plaques. To test our hypothesis, attachment of $\alpha_{\mathrm{v}} \beta_{3}$-targeted MicroMarker UCA to endothelial SVEC cells was evaluated in vitro. Attachment of tUCA in vivo and signal enhancement of the carotid plaques were assessed in the $\mathrm{ApoE}^{-1-}$ mouse model.

\section{METHODS}

A high-frequency pre-clinical ultrasound scanner, with a 256-element linear array transducer (Vevo 2100 with MS250 probe, VisualSonics, Toronto, ON, Canada) was used at $18 \mathrm{MHz}$. The transducer was operated at $10 \%$ transmit power, and a wide beam-width setting was chosen to have a low, more uniform transmit pressure over depth (Needles et al. 2010) ( 400 kPa, mechanical index $=0.1$. Side-by-side B-mode and non-linear contrast mode (amplitude modulation [Needles et al. 2010]) images were acquired at a frame rate of 20 frames/s and a dynamic range of 35. UCA was prepared from Target-Ready Vevo MicroMarker UCA (VisualSonics) according the manufacturer's instructions. The UCA was targeted with biotinylated antibodies against $\alpha_{\mathrm{v}} \beta_{3}$ integrin (Catalog No. 551380, Clone RMV-7, BD Biosciences, San Jose, CA, USA), an antibody previously successfully used to prepare $\alpha_{\mathrm{v}} \beta_{3}$-tUCA for ultrasound molecular imaging of tumor angiogenesis (Leong-Poi et al. 2003). An inactive form of biotinylated $\operatorname{IgG}(\kappa)$ (Catalog No. 553923, BD Biosciences) was used for making control UCA (cUCA).

In vitro

Murine SV40 virus-modified endothelial cells (SVEC) were purchased from ATCC (LGC Standards, Wesel, Germany) and cultured in Dulbecco's Modified Eagle's Medium/Ham's F-12 (Gibco, Life Technologies Europe, Bleiswijk, Netherlands) with penicillin-streptomycin solution $(1 \% \mathrm{v} / \mathrm{v}$ solution containing 5,000 units penicillin [Gibco] and $5 \mathrm{mg}$ streptomycin [Gibco] per milliliter) and $10 \%$ heat-inactivated fetal calf serum (Gibco) in a humidified atmosphere of $5 \% \mathrm{CO}_{2}$ at $37^{\circ} \mathrm{C}$. Cells were cultured up to passage 5 in acoustically transparent OptiCell (NUNC, Wiesbaden, Germany) chambers on only one of the two membranes until $100 \%$ confluence. $\alpha_{\mathrm{v}} \beta_{3}$ expression was determined by fluorescence immunostaining. The cells were fixed in $4 \%$ formaldehyde for $5 \mathrm{~min}$ and blocked in $5 \%$ goat serum in phosphate-buffered saline (PBS) solution for $1 \mathrm{~h}$. After fixation, $1 \times 1-\mathrm{cm}$ pieces of the OptiCell membrane containing cells were cut out. These specimens were incubated with rat anti-mouse antibody against $\alpha_{\mathrm{v}} \beta_{3}$ integrin (1:100; BD Biosciences) for $1.5 \mathrm{~h}$. After thorough washing with PBS, the specimens were incubated with goat anti-rat antibody conjugated with AlexaFluor 488 (1:1,000; Invitrogen, Groningen, Netherlands) for $1 \mathrm{~h}$. As a control, fixed cells were blocked and incubated with rat anti-mouse antibody against $\alpha_{\mathrm{v}} \beta_{3}$ integrin only or goat anti-rat antibody conjugated with 
AlexaFluor488 only. All procedures were carried out at room temperature. After incubation, the specimens were washed with PBS and embedded in Mowiol (Sigma-Aldrich, Zwijndrecht, Netherlands) with Hoechst 33342 (Invitrogen; $5 \mu \mathrm{g} / \mathrm{mL}$ ) to stain the cell nuclei. Fluorescence microscopy was performed with a fluorescence Olympus microscope equipped with an AxioCam MRc camera (Carl Zeiss, Sliedrecht, Netherlands) and 40× waterimmersed objective (LUMPlanFI, NA 0.8, Olympus).

To assess the adhesion of tUCAs to SVEC cells, the cells were cultured as previously described, and $30 \mu \mathrm{L}$ of $\alpha_{\mathrm{v}} \beta_{3}$-tUCA or cUCA was added to the cells. The OptiCell was then turned cell side up, to let UCA adhere to the cells by flotation, and incubated at $37^{\circ} \mathrm{C}$ for $5 \mathrm{~min}$. After incubation, the OptiCell was inverted (cell side down) and incubated for another $5 \mathrm{~min}$ at $37^{\circ} \mathrm{C}$ to allow UCA that did not adhere to the cells to float to the top membrane of the OptiCell chamber. For each specimen, 20 random fields of view were acquired for both UCA adhering to cells on the bottom and free-floating UCA on top of the OptiCell. The ratio of adhered UCA to total adhered plus free-floating UCA was calculated and presented as the percentage of attached UCA.

To determine whether tUCA adherent to $\alpha_{\mathrm{v}} \beta_{3}$-integrin can be detected by high-frequency non-linear contrast imaging, cells were incubated with tUCA as described above, and then the membrane of the OptiCell that did not contain the cells was cut out. Cells were washed with $37^{\circ} \mathrm{C}$ fresh warm medium and placed in the tank filled with PBS, the temperature of which was maintained at $37^{\circ} \mathrm{C}$. The 18 $\mathrm{MHz}$ probe was then positioned above the OptiCell. To prevent the overwhelming specular reflection from the OptiCell interface and to obscure the scattering signal from the sample under examination received by the US transducer, the OptiCell was placed tilted at a $20^{\circ}$ angle with respect to the direction of the ultrasound beam; thus, specular reflected US signals from the OptiCell could not reach the US transducer (Klibanov 2006). First, a 2-D image was acquired, and the tUCA in this 2-D imaging plane were destroyed using a flash burst. In addition to the 2-D images, 3-D B-mode and non-linear contrast mode images were acquired by mounting the probe on a linear stepper motor (VisualSonics). The probe was translated over $\sim 4.9 \mathrm{~mm}$, while acquiring frames every $0.032 \mathrm{~mm}$ (beam overlap percentage $\sim 50 \%$, pixel size of $0.0262 \mathrm{~mm}$ in contrast mode). The series of images was then rendered in 3-D using the Vevo 2100 3-D Mode software (VisualSonics).

In vivo

Animal experiments were approved by the regulatory authority of Maastricht University and performed in compliance with Dutch government regulation guidelines. Hypercholesterolemic male ApoE knockout mice $(\mathrm{n}=7)$ on a C57/BI6 background from an in-house breeding colony (originally from Iffa Credo, Lyon, France) were fed normal chow until the age of $50 \mathrm{wk}$. Mice were anesthetized with ketamine $(0.1 \mathrm{~g} / \mathrm{kg})$ and $x y-$ lazine $(0.02 \mathrm{~g} / \mathrm{kg})$ by subcutaneous injection and preoperative ibuprofen (subcutaneously). The animals were intubated and artificially ventilated using room air at the rate of 160 strokes/min and stroke volume of $250 \mu \mathrm{L}$ (Mouse Microvent, Hugo Sachs, Germany). The left jugular vein was exposed, and a heat-stretched polyethylene- 25 cannula was inserted $(1.5 \mathrm{~cm})$ and subcutaneously guided to the neck of the mouse. Here the catheter was fixed with sutures, extended, filled with heparinized saline $(10 \mathrm{U} / \mathrm{mL})$ and plugged. Animals were placed on the Vevo Rail System heating stage (VisualSonics), and ultrasound imaging was performed. For each animal, cUCA and tUCA (100 $\mu \mathrm{L}$ each) were injected with 20-min intervals between injections using a programmable syringe pump (11 Pico Plus Elite, Harvard Apparatus, Kent, UK) at the rate of $600 \mu \mathrm{L} / \mathrm{min}$. The focus of the transducer was set at $7 \mathrm{~mm}$, at the upper wall of the right common carotid artery. A field of view of the right common carotid artery and its bifurcation was chosen. The right salivary gland located above the right carotid was also in the imaging field. B-Mode gain was $20 \mathrm{~dB}$, and contrast gain was $30 \mathrm{~dB}$. DICOM (Digital Imaging and Communications in Medicine) images were exported to MATLAB (Version R2012 b, The MathWorks, Natick, MA, USA) for further off-line processing.

After injection of the UCA, about $10 \mathrm{~min}$ is required for UCA clearance from the blood (van Rooij et al. 2015). This waiting period also leaves more time for the tUCA to adhere to the $\alpha_{\mathrm{v}} \beta_{3}$ binding sites. Next, a series of about 300 frames $(\sim 10 \mathrm{~s})$ was acquired with high-intensity ultrasound bursts (flash with standard internal destruction burst of 10-cycle square envelope at $18 \mathrm{MHz}$ and $100 \%$ power for a total duration of exposure of $1 \mathrm{~s}$ ) in the middle to disrupt the UCA in the imaging plane.

Subsets of the images (100 frames) captured $10 \mathrm{~min}$ after injecting the UCA were used for quantification of the bound UCA in the region of interest (ROI) around the carotid plaques, the healthy part of the carotid artery and in the salivary gland. The captured frames with a flash in the middle to destroy the UCA in the imaging plane were separated into two groups: pre-flash and post-flash groups (50 frames each from pre- and post-flash groups). The noise levels in each data set were obtained by drawing a ROI in the background of a contrast frame immediately after the flash pulse and calculating the mean intensity value $(\mu)$ and standard deviation $(\sigma)$ in the ROI. Then, all image intensities below a noise threshold level of $(\mu+4) \times \sigma$ were set to zero (Daeichin et al. 2015a). Next, averaging was applied on all the frames of each pre- and post-flash group, resulting in a single mean image 
for each of these groups. The averaging emphasizes the signal of stationary contrast spots. Each of the single pre- and post-flash mean images was then smoothed using a 2 -D Gaussian filter of $3 \times 3$ pixels with sigma $=1$ to remove speckles smaller than the characteristic bubble size $(0.0786 \times 0.0786 \mathrm{~mm})$. The resulting post-flash mean images were subtracted from the pre-flash counterpart to cancel signals of non-stationary contrast spots, stationary artifacts and remaining tissue signal. In the subtracted mean images, mean intensity within each ROI was calculated and presented as molecular signals. Respiratory motion artifacts were absent and therefore not relevant.

\section{Tissue handling}

At sacrifice, blood was drawn from the right ventricular apex. Subsequently the mice were perfusion fixed via the left cardiac ventricles with $20 \mathrm{~mL}$ sodium nitroprusside $(0.1 \mathrm{mg} / \mathrm{mL}$ in PBS, Sigma-Aldrich, Seelze, Germany), followed by $1 \%$ paraformaldehyde (PFA). The right carotid arteries and salivary glands were excised, fixed in $1 \%$ PFA for $24 \mathrm{~h}$ and embedded in paraffin. The right carotid arteries and salivary glands were serially sectioned $(4 \mu \mathrm{m})$ and stained at $20-\mu \mathrm{m}$ intervals with hematoxylin and eosin (HE, Sigma-Aldrich) for microscopic examination. Serial sections were subjected to heat-induced epitope retrieval (DAKO target retrieval) and stained with rat anti-mouse MAC3 (1:400, clone M3/84, Becton \& Dickinson) for $1 \mathrm{~h}$ at room temperature to visualize plaque macrophages. Slides were subsequently incubated with biotinconjugated rabbit anti-rat secondary antibody (Jackson Immunoresearch), followed by horseradish peroxidase ABC (Vector, ABC systems), and staining was visualized using 3,3-diaminobenzidine tetrahydrochloride (brown precipitate, DAKO). Endothelial cells were stained overnight at $4{ }^{\circ} \mathrm{C}$ with CD31 primary antibody (1:50, BD Pharmingen) after trypsin treatment $(0.1 \%$ trypsin, $0.1 \% \mathrm{CaCl}_{2}, \mathrm{pH} 7.8$ ) for $20 \mathrm{~min}$ at $37^{\circ} \mathrm{C}$ (Muchir et al. 2009) for epitope retrieval. Slides were further incubated with mouse-absorbed rabbit anti-rat (Vector), horseradish peroxidase-conjugated anti-rabbit antibody (BrightVision, Immunologic) to amplify signal and visualized using diaminobenzidine.

\section{Statistical evaluation}

Statistical analysis for integrin expression and number of UCA microbubbles adherent to the SVEC cells was performed using an unpaired $t$-test. In vivo, quantified molecular signal based on video intensity of contrastenhanced sonograms of processed images in seven animals was analyzed using a paired $t$-test and expressed as medians and interquartile ranges ( $p<0.01$ was considered to indicate significance).

\section{RESULTS}

In vitro

Immunofluorescence staining of $\alpha_{\mathrm{v}} \beta_{3}$-integrin expression on SVEC cell membranes (Fig. 1f) revealed that the ligand is expressed on the cell surface, especially in cell-cell border regions. No fluorescence was observed when only the $\alpha_{\mathrm{v}} \beta_{3}$-antibody or only the goat anti-rat antibody conjugated with AlexaFluor488 was used. These stainings also prove that the $\alpha_{\mathrm{v}} \beta_{3^{-}}$ tUCA used in this study can adhere to murine endothelial cells. To examine the binding affinity of UCA, $\alpha_{\mathrm{v}} \beta_{3^{-}}$ tUCA or cUCA was incubated with live SVEC cells. We observed that significantly more (3.7 times more, $p<0.0001$ ) tUCA (Fig. 1b) than cUCA attached to the cells (Fig. 1a).

Figure $2 \mathrm{a}$ is a schematic of the imaging setup. Figure 2b illustrates the ultrasonic signals of SVEC cells to which tUCA was bound. The contrast-to-tissue ratio was $30 \mathrm{~dB}$. In Figure 2b, the gray-scale B-mode image overlies the contrast-mode image. The band in the middle of Figure $2 \mathrm{~b}$ showing no green signal indicates the destruction of the tUCA with the flash burst.

\section{In vivo}

To examine further the application of $\alpha_{\mathrm{v}} \beta_{3}$-tUCA for imaging $\alpha_{\mathrm{v}} \beta_{3}$-integrin expression in vivo, the following locations were examined in $\mathrm{ApoE}^{-/-}$mice: atherosclerotic lesions at the bifurcation of the carotid artery, part of the wall of the common carotid artery containing no atherosclerotic lesions and the salivary gland. Figure $3 \mathrm{a}$ is a micrograph of an $\mathrm{ApoE}^{-1-}$ mouse indicating the anatomic structure and presence of atherosclerotic lesions in the aortic arch (AA), brachiocephalic trunk (BT) and right carotid bifurcation (RCB). In Figure $3 b$ and $\mathrm{c}$ are examples of cross-sectional histopathologic sections revealing the morphology of the carotid artery and the atherosclerosis lesions are presented. Large and advanced atherosclerosis lesions at and around the carotid bifurcation are visible in Figure $3 \mathrm{~b}$, and the absence of atherosclerotic lesions in the right common carotid (RCC) artery can be observed in Figure 3c.

Representative B-mode and contrast mode images of the right carotid and salivary gland; analyzed ROIs for the plaque area and salivary gland; and a no-plaque ROI in the common carotid are provided in Figure 4. Similar to in vitro results, there was evident enhancement of the ultrasound signal from the $\alpha_{\mathrm{v}} \beta_{3}$-tUCA adhering to the vessel walls in the carotid bifurcation (Fig. 4c) and salivary gland (Fig. 4e) after applying our quantification method. Only a weak molecular signal was detected in the case of cUCA injections (Fig. 4d, f). Enhancement of the ultrasound signal in the no-plaque ROI (Fig. 4g, h) was significantly $(p<0.01)$ lower than that in the plaque ROI. 

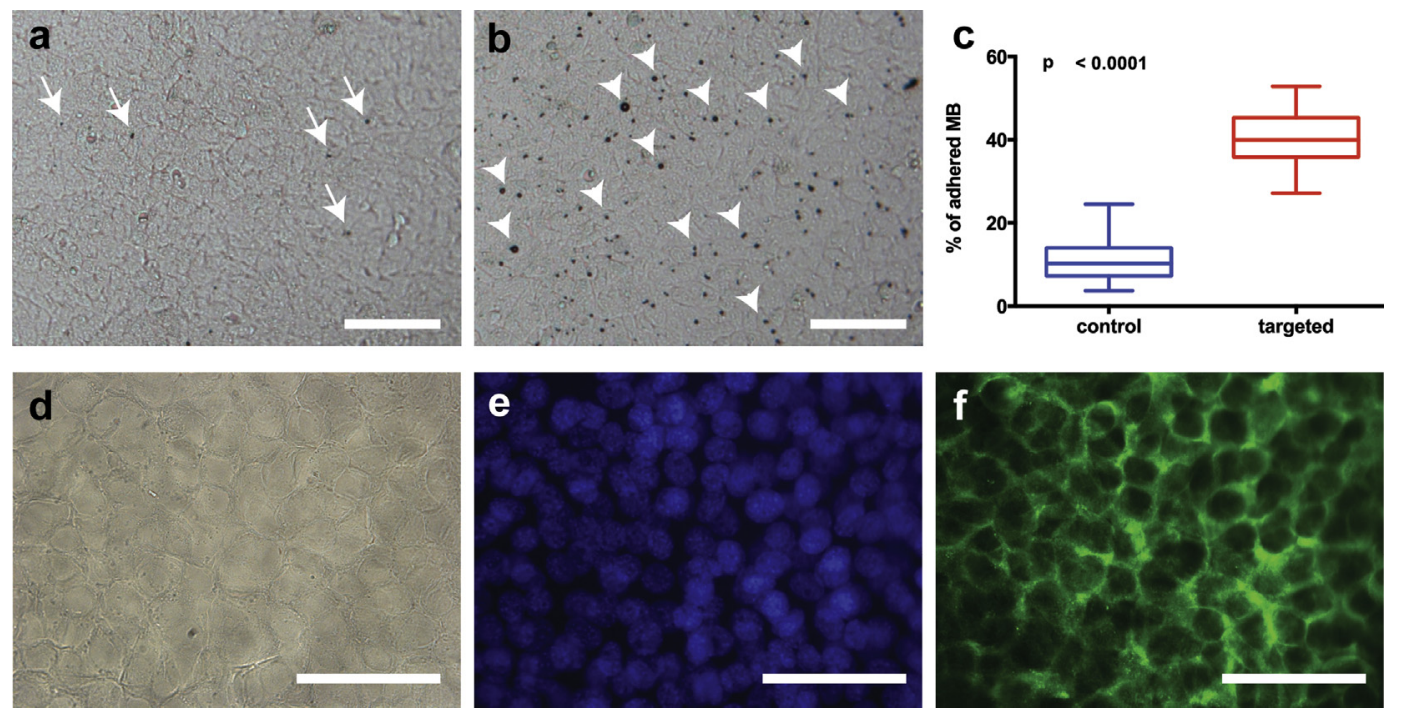

Fig. 1. $\alpha_{\mathrm{v}} \beta_{3}$-Integrin expression in cultured SVEC cells. $(\mathrm{a}, \mathrm{b})$ Bright-field images of control ultrasound contrast agent (cUCA) (a) and targeted ultrasound contrast agent (tUCA) (b). Arrows point to cUCA, and arrowheads point to tUCA. (c) The percentages of tUCA and cUCA microbubbles that adhered to SVEC cells are illustrated as interquartile ranges. (d, e) Corresponding bright-field image (d) and staining of cell nuclei (e). Immunofluorescence staining of $\alpha_{\mathrm{v}} \beta_{3}$-integrin expressed on cell membrane of SVECs (f). Bar $=50 \mu \mathrm{m}$.

Quantitative analysis of the sonograms of the plaque ROI revealed that the difference between the molecular signals using $\alpha_{\mathrm{v}} \beta_{3}$-tUCA (4.25 \pm 0.84 arbitrary units [a.u.]) and those using cUCA (1.08 \pm 0.39 a.u.) was statistically significant (Fig. 5). There was also a difference in signal intensity for the salivary gland $(6.61 \pm 1.23$ a.u. for tUCA vs. $2.63 \pm 0.60$ a.u. for cUCA) (Fig. 5). However there was no statistically significant difference for $\alpha_{\mathrm{v}} \beta_{3}$-tUCA and cUCA in the noplaque ROI (1.16 \pm 0.24 a.u. for tUCA and $0.41 \pm 0.07$ a.u. cUCA) (Fig. 5). Also, the molecular signal in the plaque ROI ( $4.25 \pm 0.84$ a.u.) was significantly higher than that for the no-plaque ROI $(1.16 \pm 0.24$ a.u. $)$ for the tUCA. As expected, this difference was not significant for the cUCA (1.08 \pm 0.39 a.u. vs. $0.41 \pm 0.07$ a.u. $)$.

To validate the results of ultrasonography, the carotid artery and salivary gland of mice were harvested and subsequently analyzed for the presence of blood vessels and macrophages by CD31 and MAC3 staining, respectively. Results indicated expanded adventitial vasa vasorum and numerous macrophages in the carotid artery plaques (Fig. 6a, c) and microvessels and macrophages in the salivary gland (Fig. 6b, d).

Also to validate the results of ultrasonography, the carotid artery and salivary gland of mice were harvested and subsequently analyzed for the presence of $\alpha_{\mathrm{v}} \beta_{3}$ expression, blood vessels and macrophages by $\alpha_{\mathrm{v}} \beta_{3}$,
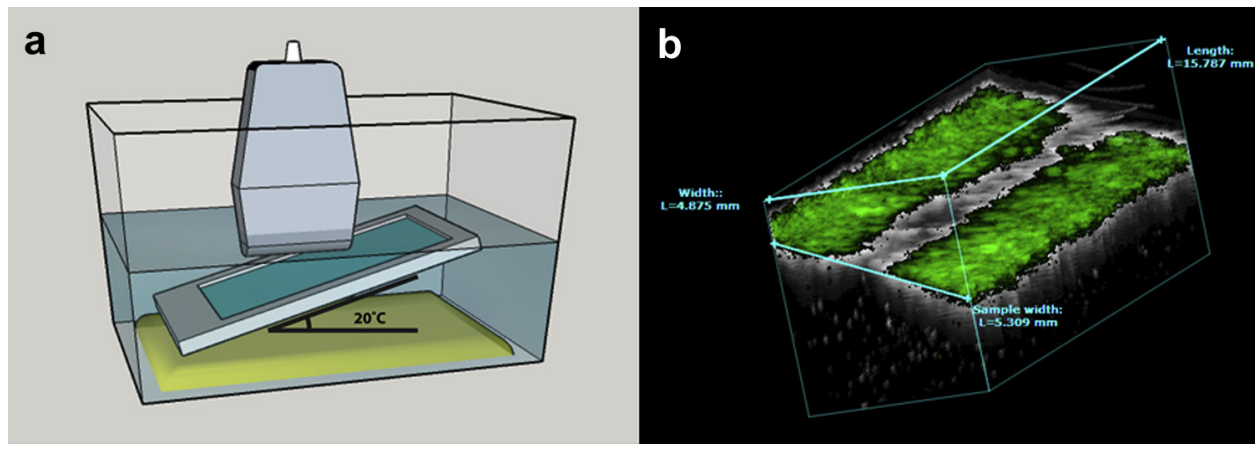

Fig. 2. Ultrasound molecular imaging of $\alpha_{\mathrm{v}} \beta_{3}$-tUCA expression in vitro. (a) Schematic of in vitro ultrasound molecular imaging of $\alpha_{\mathrm{v}} \beta_{3}$-tUCA expression in vitro. (b) B-Mode (gray) image with overlying non-linear contrast mode (green) image in three dimensions to detect $\alpha_{\mathrm{v}} \beta_{3}$ expression via $\alpha_{\mathrm{v}} \beta_{3}$-tUCA adherent to SVEC cells cultured in an OptiCell. Imaging was performed with the Vevo 2100 ultrasound imaging system and MS250 probe at $18 \mathrm{MHz}$. 



Fig. 3. Micrograph and cross-sectional histopathologic sections of a 50-wk-old ApoE ${ }^{-1-}$ mouse. (a) Anatomic structure of heart, left carotid (LC) and right carotid; atherosclerosis lesions in the aortic arch (AA), brachiocephalic trunk (BT) and right carotid bifurcation (RCB); and absence of lesions in the right common carotid (RCC). (b) Corresponding hematoxylin and eosin-stained slices just before, at and just after the carotid bifurcation where the advanced atherosclerosis lesions are visible. (c) Corresponding hematoxylin and eosin-stained slice from the middle of the right common carotid (RCC) where there is no atherosclerotic lesion.

CD31 and MAC3 staining, respectively. Results indicated the presence of $\alpha_{\mathrm{v}} \beta_{3}$, expanded adventitial vasa vasorum, and numerous macrophages in the carotid artery plaques (Fig. 6a, c) and microvessels and macrophages in the salivary gland (Fig. 6b, d).

\section{DISCUSSION}

Our in vitro and in vivo results revealed successful binding of tUCA to $\alpha_{\mathrm{v}} \beta_{3}$-integrin, as well as successful detection of $\alpha_{\mathrm{v}} \beta_{3}$-tUCA corresponding to the intensity of $\alpha_{\mathrm{v}} \beta_{3}$-integrin expression on endothelial cells. Expression of $\alpha_{\mathrm{v}} \beta_{3}$ was confirmed by immunocytochemistry in vitro. In vivo, immunohistochemical $\alpha_{\mathrm{v}} \beta_{3}$ signals in plaques and the salivary gland are most likely derived from endothelial cells and macrophages, known to express $\alpha_{\mathrm{v}} \beta_{3}$-integrin (Antonov et al. 2004; Brooks et al. 1994; Hoshiga et al. 1995).

It is known that macrophages play an important role in the pathogenesis of atherosclerosis and strongly correlate with plaque vulnerability (Boyle 2005; Redgrave et al. 2006). The expression of $\alpha_{\mathrm{v}} \beta_{3}$-integrin on activated macrophages, which are recruited to the arterial wall, had been confirmed earlier (Antonov et al. 2004). However, our results are especially valuable because they can provide a strategy for direct and selective intraplaque neovascularization evaluation in terms of spatial extent and amount of endothelial $\alpha_{\mathrm{v}} \beta_{3}$-integrin in a non-invasive or minimally invasive manner. Such separation between $\alpha_{v} \beta_{3}$-integrin expressed on macrophages and endothelial cells is possible with ultrasound molecular imaging because UCAs remain exclusively intravascular on intravenous administration, thereby minimizing non-specific signals from extravasated contrast material. This separation was not possible for the $\alpha_{\mathrm{v}} \beta_{3}$ expression studies of atherosclerosis with near-infrared optical imaging (Tedesco et al. 2009), magnetic resonance imaging (Winter et al. 2003) and positron emission tomography (Laitinen et al. 2009) because the contrast agents used in these studies are small and can therefore extravasate. Although it can be argued that the micron-sized microbubbles in UCAs can extravasate from the leaky adventitial vasa vasorum, further investigation is required to confirm such a hypothesis.

Numerous investigators have adopted approaches in which ultrasound molecular images have been acquired through the use of UCAs targeted to many biomarkers related to atherosclerosis, such as CD81 (Yan et al. 2012), ICAM-1 (Demos et al. 1999), VCAM-1 (Hamilton et al. 2004; Khanicheh et al. 2013a, 2013b; Liu et al. 2013), P-selectin (Lindner et al. 2001; Liu et al. 2013), platelet glycoprotein $\mathrm{Ib} \alpha$ (Khanicheh et al. 2013b; Liu et al. 2013; Shim et al. 2015) and von Willebrand factor (Shim et al. 2015). However, to the best of our knowledge, this is the first study reporting 



Fig. 4. Molecular sonogram of carotid artery vessels and salivary gland. (a) B-Mode image of the right carotid and right salivary gland with a region of interest (ROI) in the salivary gland (yellow lines), around the plaque at the carotid bifurcation (yellow rectangle) and around the common carotid artery (yellow rectangle) where no plaque was present. The yellow dashed rectangle indicates the size of the sonograms in (e) and (f). (b) Non-linear contrast mode image (maximum intensity projection over 100 frames) of the right carotid and salivary gland after injection of the ultrasound contrast agent. ROIs are represented by yellow lines (salivary gland) and rectangles (plaque ROI and no plaque ROI). (c) Detected bound targeted UCA (tUCA) in the plaque ROI. (d) Detected bound control UCA (cUCA) plaque ROI. (e) Detected bound tUCA in the salivary gland ROI. (f) Detected bound cUCA in the salivary gland ROI. (g) Detected tUCA in the ROI around the common carotid artery wall, where no plaque is present. (h) Detected cUCA in the ROI around the common carotid artery wall, where no plaque is present.

successful in vivo ultrasound molecular imaging of adventitial vasa vasorum in atherosclerotic plaques using UCA targeted to $\alpha_{\mathrm{v}} \beta_{3}$-integrin in a mouse model of



Fig. 5. Quantification of molecular signals (medians and interquartile ranges) in the plaque region of interest (ROI), salivary gland and no-plaque ROI for control (cUCA) and targeted (tUCA) ultrasound contrast agent. $* p<0.01$. atherosclerosis. The advantage of using $\alpha_{\mathrm{v}} \beta_{3}$-integrin as a target for tUCA over other atherosclerotic biomarkers, such as CD81, ICAM-1, VCAM-1, P-selectin, platelet glycoprotein $\mathrm{Ib} \alpha$ and von Willebrand factor, is the ability to identify intraplaque neovascularization, which has been identified as an independent predictor of intraplaque hemorrhage and plaque rupture. The $\alpha_{\mathrm{v}} \beta_{3}$-tUCA could therefore be used to assess the risk of rupture of atherosclerotic plaques. Use of $\alpha_{\mathrm{v}} \beta_{3}$-tUCA to assess adventitial vasa vasorum will have advantages over use of nontargeted microbubbles that are currently already used in the clinic for adventitial vasa vasorum assessment (Staub et al. 2010; van den Oord et al. 2015). These advantages include (i) a better assessment of adventitial vasa vasorum and intraplaque neovascularization as the plaque can be imaged in three dimensions by, for example, mechanical stepping of the transducer; and (ii) assessment of the far-wall plaque which is now very limited for non-targeted microbubbles because of the pseudo-enhancement artifact resulting from freefloating microbubbles in the lumen (ten Kate et al. 2012). 

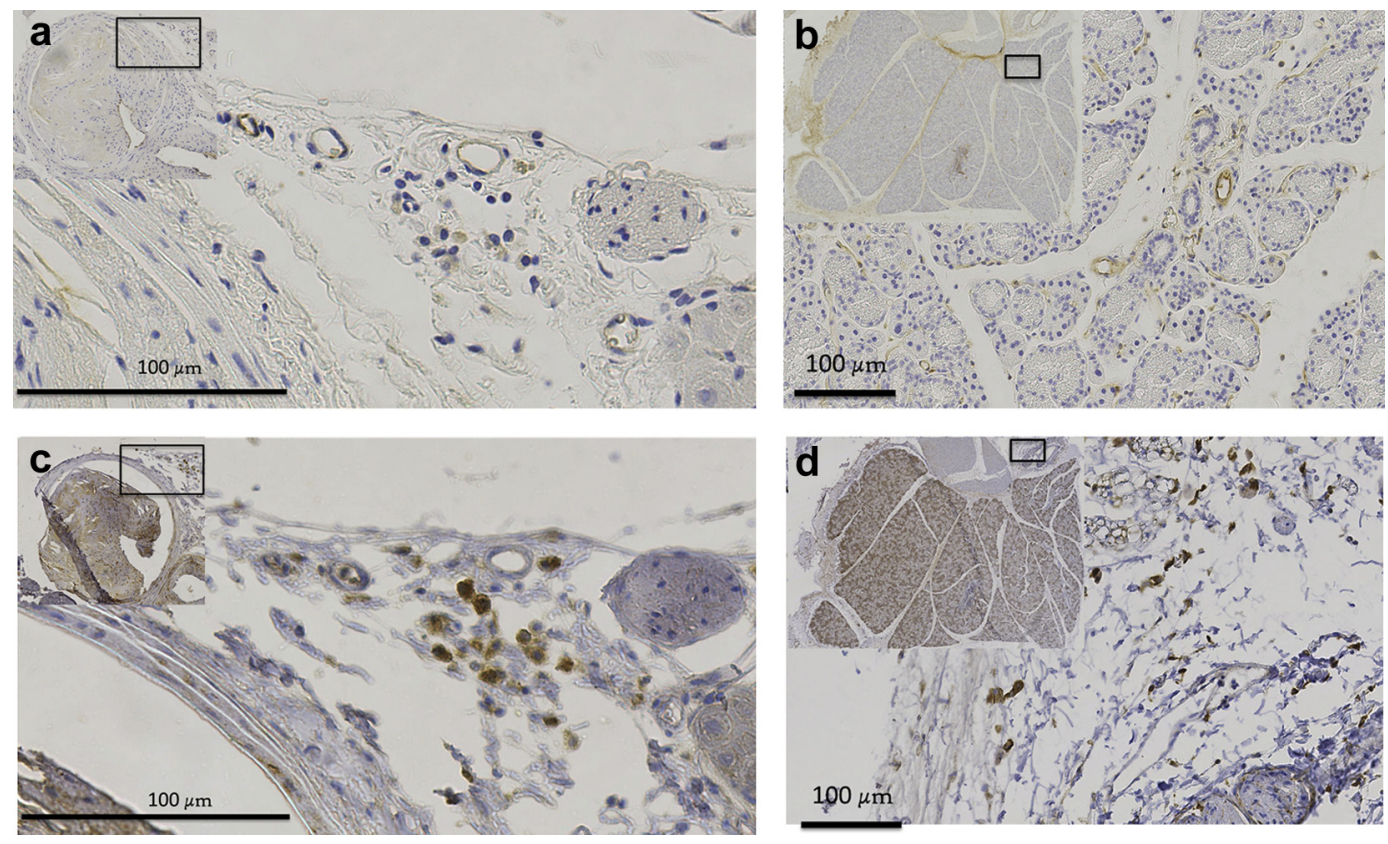

Fig. 6. (a, b) Microvessels (CD31 staining) and (c, d) macrophages (MAC3 staining) in atherosclerosis plaque of the right carotid artery $(a, c)$ and right salivary gland $(b, d)$. Insets show origin of magnification.

In our study, we chose the carotid artery vessels as the target for examination for the following reasons: First, it is believed that the carotid artery is the most reproducible site for studies of lesions in mice (Ni et al. 2009; Rigatelli and Zanchetta 2005). Second, the carotid artery vessels are superficially located and hence readily accessible for ultrasound imaging systems. Third, the salivary gland, which is in the field of view on top of the carotid, is a suitable internal positive control for binding of tUCA in such a murine model. Finally, the common carotid distal of the bifurcation is usually free from lesions and, hence, an ideal intra-animal negative control because it is in the same field of view.

We observed $\alpha_{\mathrm{v}} \beta_{3}$-tUCA attached to the middle part of the common carotid artery, a location where no atherosclerotic lesions were present. This may be explained by $\alpha_{\mathrm{v}} \beta_{3}$-integrin expression in normal arteries, as reported previously (Hoshiga et al. 1995). However, the intensity of $\alpha_{\mathrm{v}} \beta_{3}$ expression in the healthy part of the common carotid artery was significantly lower than that in the plaque ROI. As expected, there was no statistical significant difference between the molecular signal in the plaque ROI and that in the no-plaque ROI for the cUCA, as well as for tUCA versus cUCA in the part of the vessel without plaques. Subsequent work to further improve the signalto-baseline would add to the power of this technique.

The salivary gland is a large and very well vascularized organ, which is located above the right carotid in our imaging field of view. Microvessel density in the gland is high, hence so is the associated $\alpha_{\mathrm{v}} \beta_{3}$-integrin expression.
Therefore, it is an ideal target as an internal positive control for successful binding of $\alpha_{\mathrm{v}} \beta_{3}$-tUCA to its targets. Our immunocytochemistry analysis of the salivary glands also confirmed the presence of macrophages and microvessels in this gland.

Our quantification method ensures that only the signal from bound UCA is enhanced and considered as molecular signal. Shortly after injection of the UCA, the intensity of contrast in the ROI increased rapidly and reached a maximum, and this was followed by a slow decay in intensity for both tUCA and cUCA. However, $10 \mathrm{~min}$ after the injection, because of the binding of the tUCA to the $\alpha_{\mathrm{v}} \beta_{3}$-integrin, the level of intensity is expected to be higher for tUCA than for cUCA. Ideally, 10 min after injection of cUCA, image intensity in the ROI should fall back to the baseline level (similar to the level before UCA injection), and there should be no difference in image intensity before and after the flash pulse. On the other hand, there will be a difference in the intensity levels for tUCA before and after the flash because of the destruction of bound tUCA, which is a measure of the molecular signals in the ROI. Even 10 min after injection, there will be recirculating unbound UCA for both tUCA and cUCA injections. Therefore, the actual difference in the intensity of the pre- and post-flash frames depends on the amount of both bound and unbound UCA in the ROI. The increase in intensity after the flash is also an indication of the presence of recirculating UCA. The processing steps, such as averaging pre- and post-flash frames and subtracting the result frames from each other, ensures 
that tissue artifacts are minimized and only the stationary contrast spots are enhanced. We had previously found, in both in vitro and in vivo comparison studies, that the amplitude-modulation pulse sequence used to extract the non-linear response of the UCA at the fundamental frequency is a suitable non-linear contrast mode for imaging targets such as mouse carotid artery with the imaging platform used in this study (Daeichin et al. 2015b).

There are several limitations to this study. First, in the preparation of the targeted UCA, biotin-avidin bridging was used to non-covalently and very stably couple the $\alpha_{\mathrm{v}} \beta_{3}$ antibody to the lipid microbubble coating. However, this strategy may not be translated to humans, as avidin is immunogenic in humans (Petronzelli et al. 2010). On the other hand, this avidinbiotin coupling can be avoided by covalently linking the antibody to the lipid microbubble coating. A covalent linkage of cyclic RGD, a human compatible ligand for $\alpha_{\mathrm{v}} \beta_{3}$, has already been reported for tUCA (Anderson et al. 2011). In addition, these components are commercially available. Second, it cannot be assumed that the murine expression of $\alpha_{\mathrm{v}} \beta_{3}$ is fully identical to clinical disease-related $\alpha_{\mathrm{v}} \beta_{3}$ expression. In the clinical setting, more complex factors such as disease-related inducers, individual differences and intricate signal pathways are often involved in the regulation of $\alpha_{\mathrm{v}} \beta_{3}$ expression. Although there remains a long road to translation of this technique from the animal model to the clinical situation, it would be desirable to relate the level of videointensity signal from the tUCA to the stage of the disease and to predict the risk of future clinical cardiovascular events. Also, precise spatial correlation between ultrasonography and immunohistology is not always possible because of the difficulty involved in spatially matching the ultrasound plane with histologic sections and the fact that 2-D ultrasonography is formed from signals received over a beam elevation of almost a millimeter. Accuracy of $\alpha_{\mathrm{v}} \beta_{3}$ quantification using the tUCA may be limited by some degree of non-specific binding because of the expression of $\alpha_{\mathrm{v}} \beta_{3}$ by the vascular endothelium. In addition, more complex factors, such as acoustic radiation force, UCA concentration, blood flow velocity and tUCA affinity, are involved and need to be further investigated.

\section{CONCLUSIONS}

This article describes the successful preparation of $\alpha_{\mathrm{v}} \beta_{3}$-targeted microbubbles and the potential of targetspecific UCA to quantitatively detect the expression of $\alpha_{\mathrm{v}} \beta_{3}$ integrin in vitro and in vivo. Our initial experience in molecular ultrasonography using $\alpha_{\mathrm{v}} \beta_{3}$-tUCA has indicated that it may enable in vitro and in vivo molecular imaging of $\alpha_{\mathrm{v}} \beta_{3}$ expression on actively sprouting vascular endothelium. This imaging modality may provide reference values for relative expression of $\alpha_{\mathrm{v}} \beta_{3}$ and information likely to be very useful to address the detection, prognosis and vulnerable potential of atherosclerosis or susceptibility to anti-atherosclerosis drugs.

Acknowledgments-This research was supported by the Center for Translational Molecular Medicine and the Netherlands Heart Foundation (PARISk grant 01C-202, www.ctmm.nl), and the German Research Foundation (SFB824).-We greatly thank all colleagues for their help and support, which made the experiments possible, especially Peter Leenders, Agnieszka Strzelecka and Jacques Debets (Department of Pharmacology, Maastricht University, Maastricht, Netherlands), and Jeroen Otten, and Anique Janssen (Department of Pathology, Maastricht University Medical Center, Maastricht, Netherlands).

\section{REFERENCES}

Alonso A, Della Martina A, Stroick M, Fatar M, Griebe M, Pochon S, Schneider M, Hennerici M, Allemann E, Meairs S. Molecular imaging of human thrombus with novel abciximab immunobubbles and ultrasound. Stroke 2007;38:1508-1514.

Anderson CR, Hu X, Zhang H, Tlaxca J, Decleves AE, Houghtaling R, Sharma K, Lawrence M, Ferrara KW, Rychak JJ. Ultrasound molecular imaging of tumor angiogenesis with an integrin targeted microbubble contrast agent. Invest Radiol 2011;46:215-224.

Antonov AS, Kolodgie FD, Munn DH, Gerrity RG. Regulation of macrophage foam cell formation by $\alpha \mathrm{v} \beta 3$ integrin: Potential role in human atherosclerosis. Am J Pathol 2004;165:247-258.

Barger AC, Beeuwkes R 3rd, Lainey LL, Silverman KJ. Hypothesis: Vasa vasorum and neovascularization of human coronary arteries. A possible role in the pathophysiology of atherosclerosis. N Engl J Med 1984;310:175-177.

Bettinger T, Bussat P, Tardy I, Pochon S, Hyvelin JM, Emmel P, Henrioud S, Biolluz N, Willmann JK, Schneider M, Tranquart F. Ultrasound molecular imaging contrast agent binding to both e- and pselectin in different species. Invest Radiol 2012;47:516-523.

Boyle JJ. Macrophage activation in atherosclerosis: Pathogenesis and pharmacology of plaque rupture. Curr Vasc Pharmacol 2005;3:63-68.

Brooks PC, Clark RA, Cheresh DA. Requirement of vascular integrin alpha v beta 3 for angiogenesis. Science 1994;264:569-571.

Daeichin V, Akkus Z, Skachkov I, Kooiman K, Needles A, Sluimer J, Janssen B, Daemen MJ, van der Steen AF, de Jong N, Bosch JG. Quantification of bound microbubbles in ultrasound molecular imaging. IEEE Trans Ultrason Ferroelectr Freq Control 2015a;62:1190-1200.

Daeichin V, Bosch JG, Needles A, Foster FS, van der Steen A, de Jong N. Subharmonic, non-linear fundamental and ultraharmonic imaging of microbubble contrast at high frequencies. Ultrasound Med Biol 2015b;41:486-497.

Davidson BP, Chadderdon SM, Belcik JT, Gupta S, Lindner JR. Ischemic memory imaging in nonhuman primates with echocardiographic molecular imaging of selectin expression. J Am Soc Echocardiog 2014;27:786-793.e2.

Dayton PA, Ferrara KW. Targeted imaging using ultrasound. J Magn Reson Imaging 2002;16:362-377.

Demos SM, Alkan-Onyuksel H, Kane BJ, Ramani K, Nagaraj A, Greene R, Klegerman M, McPherson DD. In vivo targeting of acoustically reflective liposomes for intravascular and transvascular ultrasonic enhancement. J Am Coll Cardiol 1999;33:867-875.

Deshpande N, Ren Y, Foygel K, Rosenberg J, Willmann JK. Tumor angiogenic marker expression levels during tumor growth: Longitudinal assessment with molecularly targeted microbubbles and us imaging. Radiology 2011;258:804-811.

Ellegala DB. Imaging tumor angiogenesis with contrast ultrasound and microbubbles targeted to v 3. Circulation 2003;108:336-341.

Greis C. Ultrasound contrast agents as markers of vascularity and microcirculation. Clin Hemorheol Microcirc 2009;43:1-9.

Hamilton AJ, Huang SL, Warnick D, Rabbat M, Kane B, Nagaraj A, Klegerman M, McPherson DD. Intravascular ultrasound molecular 
imaging of atheroma components in vivo. J Am Coll Cardiol 2004; 43:453-460.

Haubner R. Alphavbeta3-integrin imaging: A new approach to characterise angiogenesis? Eur J Nucl Med Mol Imaging 2006;1:54-63.

Hauff P, Reinhardt M, Briel A, Debus N, Schirner M. Molecular targeting of lymph nodes with 1-selectin ligand-specific us contrast agent: A feasibility study in mice and dogs. Radiology 2004;231:667-673.

Hellings WE, Peeters W, Moll FL, Piers SR, van Setten J, Van der Spek PJ, de Vries JP, Seldenrijk KA, De Bruin PC, Vink A, Velema E, de Kleijn DP, Pasterkamp G. Composition of carotid atherosclerotic plaque is associated with cardiovascular outcome: A prognostic study. Circulation 2010;121:1941-1950.

Hoshiga M, Alpers CE, Smith LL, Giachelli CM, Schwartz SM. Alpha-v beta-3 integrin expression in normal and atherosclerotic artery. Circ Res 1995;77:1129-1135.

Hynes RO. Integrins: A family of cell surface receptors. Cell 1987;48: 549-554.

Kaufmann BA. Ultrasound molecular imaging of atherosclerosis. Cardiovasc Res 2009;83:617-625.

Kaufmann BA, Lindner JR. Molecular imaging with targeted contrast ultrasound. Curr Opin Biotechnol 2007;18:11-16.

Khanicheh E, Mitterhuber M, Xu L, Haeuselmann SP, Kuster GM, Kaufmann BA. Noninvasive ultrasound molecular imaging of the effect of statins on endothelial inflammatory phenotype in early atherosclerosis. PloS One 2013a;8:e58761.

Khanicheh E, Qi Y, Xie A, Mitterhuber M, Xu L, Mochizuki M, Daali Y, Jaquet V, Krause KH, Ruggeri ZM, Kuster GM, Lindner JR, Kaufmann BA. Molecular imaging reveals rapid reduction of endothelial activation in early atherosclerosis with apocynin independent of antioxidative properties. Arterioscl Thromb Vasc Biol 2013b;33: 2187-2192.

Klibanov AL. Microbubble contrast agents: Targeted ultrasound imaging and ultrasound-assisted drug-delivery applications. Invest Radiol 2006;41:354-362.

Laitinen I, Saraste A, Weidl E, Poethko T, Weber AW, Nekolla SG, Leppänen P, Ylä-Herttuala S, Hölzlwimmer G, Walch A, Esposito I, Wester H-J, Knuuti J, Schwaiger M. Evaluation of $\alpha \mathrm{v} \beta 3$ integrin-targeted positron emission tomography tracer ${ }^{18} \mathrm{~F}$-galacto-RGD for imaging of vascular inflammation in atherosclerotic mice. Circ Cardiovasc Imaging 2009;2:331-338.

Langheinrich AC, Kampschulte M, Buch T, Bohle RM. Vasa vasorum and atherosclerosis- Quid novi? Thromb Haemost 2007;97: 873-879.

Lanza GM, Wallace KD, Scott MJ, Cacheris WP, Abendschein DR, Christy DH, Sharkey AM, Miller JG, Gaffney PJ, Wickline SA. A novel site-targeted ultrasonic contrast agent with broad biomedical application. Circulation 1996;94:3334-3340.

Leong-Poi H, Christiansen J, Klibanov AL, Kaul S, Lindner JR. Noninvasive assessment of angiogenesis by ultrasound and microbubbles targeted to alpha(v)-integrins. Circulation 2003;107:455-460.

Lindner JR. Microbubbles in medical imaging: Current applications and future directions. Nat Rev Drug Discov 2004;3:527-533.

Lindner JR. Contrast ultrasound molecular imaging of inflammation in cardiovascular disease. Cardiovasc Res 2010;26:116.

Lindner JR, Song J, Christiansen J, Klibanov AL, Xu F, Ley K. Ultrasound assessment of inflammation and renal tissue injury with microbubbles targeted to p-selectin. Circulation 2001;104:2107-2112.

Liu Y, Davidson BP, Yue Q, Belcik T, Xie A, Inaba Y, McCarty OJ, Tormoen GW, Zhao Y, Ruggeri ZM, Kaufmann BA, Lindner JR. Molecular imaging of inflammation and platelet adhesion in advanced atherosclerosis: Effects of antioxidant therapy with NADPH oxidase inhibition. Circ Cardiovasc Imaging 2013;6:74-82.

Michel JB, Virmani R, Arbustini E, Pasterkamp G. Intraplaque haemorrhages as the trigger of plaque vulnerability. Eur Heart J 2011;32: 1977-1985.

Moreno PR, Purushothaman KR, Fuster V, Echeverri D, Truszczynska H, Sharma SK, Badimon JJ, O’Connor WN. Plaque neovascularization is increased in ruptured atherosclerotic lesions of human aorta: Implications for plaque vulnerability. Circulation 2004;110:2032-2038.

Moreno PR, Purushothaman KR, Sirol M, Levy AP, Fuster V. Neovascularization in human atherosclerosis. Circulation 2006; 113:2245-2252.
Muchir A, Shan J, Bonne G, Lehnart SE, Worman HJ. Inhibition of extracellular signal-regulated kinase signaling to prevent cardiomyopathy caused by mutation in the gene encoding a-type lamins. Hum Mol Genet 2009;18:241-247.

Naghavi M, Libby P, Falk E, Casscells SW, Litovsky S, Rumberger J, Badimon JJ, Stefanadis C, Moreno P, Pasterkamp G, Fayad Z, Stone PH, Waxman S, Raggi P, Madjid M, Zarrabi A, Burke A, Yuan C, Fitzgerald PJ, Siscovick DS, de Korte CL, Aikawa M, Airaksinen KE, Assmann G, Becker CR, Chesebro JH, Farb A, Galis ZS, Jackson C, Jang IK, Koenig W, Lodder RA, March K, Demirovic J, Navab M, Priori SG, Rekhter MD, Bahr R, Grundy SM, Mehran R, Colombo A, Boerwinkle E, Ballantyne C, Insull W Jr, Schwartz RS, Vogel R, Serruys PW, Hansson GK, Faxon DP, Kaul S, Drexler H, Greenland P, Muller JE, Virmani R, Ridker PM, Zipes DP, Shah PK, Willerson JT. From vulnerable plaque to vulnerable patient: A call for new definitions and risk assessment strategies. Part II. Circulation 2003;108:1772-1778.

Needles A, Arditi M, Rognin NG, Mehi J, Coulthard T, Bilan-Tracey C, Gaud E, Frinking P, Hirson D, Foster FS. Nonlinear contrast imaging with an array-based micro-ultrasound system. Ultrasound Med Biol 2010;36:2097-2106.

Ni M, Wang Y, Zhang M, Zhang P-F, Ding S-F, Liu CX, Liu XL, Zhao YX, Zhang Y. Atherosclerotic plaque disruption induced by stress and lipopolysaccharide in apolipoprotein e knockout mice. Am J Physiol Heart Circ Physiol 2009;296: H1598-H1606.

Palmowski M, Huppert J, Ladewig G, Hauff P, Reinhardt M, Mueller MM, Woenne EC, Jenne JW, Maurer M, Kauffmann GW, Semmler W, Kiessling F. Molecular profiling of angiogenesis with targeted ultrasound imaging: Early assessment of antiangiogenic therapy effects. Mol Cancer Ther 2008;7:101-109.

Petronzelli F, Pelliccia A, Anastasi AM, Lindstedt R, Manganello S, Ferrari LE, Albertoni C, Leoni B, Rosi A, D’Alessio V, Deiana K, Paganelli G, De Santis R. Therapeutic use of avidin is not hampered by antiavidin antibodies in humans. Cancer Biother Radiopharm 2010;25:563-570.

Purushothaman KR, Fuster V, O'Connor WN, Moreno PR. Neovascularization is the most powerful independent predictor for progression to disruption in high-risk atherosclerotic plaques. J Am Coll Cardiol 2003;41:352-353.

Rademakers T, Douma K, Hackeng TM, Post MJ, Sluimer JC, Daemen MJ, Biessen EA, Heeneman S, van Zandvoort MA. Plaque-associated vasa vasorum in aged apolipoprotein e-deficient mice exhibit proatherogenic functional features in vivo. Arterioscler Thromb Vasc Biol 2013;33:249-256.

Redgrave JN, Lovett JK, Gallagher PJ, Rothwell PM. Histological assessment of 526 symptomatic carotid plaques in relation to the nature and timing of ischemic symptoms: The Oxford Plaque study. Circulation 2006;113:2320-2328.

Rigatelli G, Zanchetta M. Endovascular therapies for noncoronary atherosclerosis in the elderly: Aortoiliac and femorotibial lesions. Am J Geriatr Cardiol 2005;14:195-199.

Shelton SE, Lindsey BD, Tsuruta JK, Foster FS, Dayton PA. Molecular acoustic angiography: A new technique for high-resolution superharmonic ultrasound molecular imaging. Ultrasound Med Biol 2016;42:769-781.

Shim CY, Liu YN, Atkinson T, Xie A, Foster T, Davidson BP, Treible M, Qi Y, Lopez JA, Munday A, Ruggeri Z, Lindner JR. Molecular imaging of platelet-endothelial interactions and endothelial von Willebrand factor in early and mid-stage atherosclerosis. Circ Cardiovasc Imaging 2015;8:e002765.

Sluimer JC, Gasc JM, van Wanroij JL, Kisters N, Groeneweg M, Sollewijn Gelpke MD, Cleutjens JP, van den Akker LH, Corvol P, Wouters BG, Daemen MJ, Bijnens AP. Hypoxia, hypoxiainducible transcription factor, and macrophages in human atherosclerotic plaques are correlated with intraplaque angiogenesis. J Am Coll Cardiol 2008;51:1258-1265.

Staub D, Patel MB, Tibrewala A, Ludden D, Johnson M, Espinosa P, Coll B, Jaeger KA, Feinstein SB. Vasa vasorum and plaque neovascularization on contrast-enhanced carotid ultrasound imaging correlates with cardiovascular disease and past cardiovascular events. Stroke 2010;41:41-47. 
Stieger SM, Dayton PA, Borden MA, Caskey CF, Griffey SM, Wisner ER, Ferrara KW. Imaging of angiogenesis using cadence contrast pulse sequencing and targeted contrast agents. Contrast Media Mol Imaging 2008;3:9-18.

Streeter JE, Herrera-Loeza SG, Neel NF, Yeh JJ, Dayton PA. A comparative evaluation of ultrasound molecular imaging, perfusion imaging, and volume measurements in evaluating response to therapy in patient-derived xenografts. Technol Cancer Res Treat 2013;12:311-321.

Tedesco MM, Terashima M, Blankenberg FG, Levashova Z, Spin JM, Backer MV, Backer JM, Sho M, Sho E, McConnell MV, Dalman RL. Analysis of in situ and ex vivo vascular endothelial growth factor receptor expression during experimental aortic aneurysm progression. Arterioscler Thromb Vasc Biol 2009;29: $1452-1459$.

ten Kate GL, Renaud GG, Akkus Z, van den Oord SC, ten Cate FJ, Shamdasani V, Entrekin RR, Sijbrands EJ, de Jong N, Bosch JG, Schinkel AF, van der Steen AF. Far-wall pseudoenhancement during contrast-enhanced ultrasound of the carotid arteries: Clinical description and in vitro reproduction. Ultrasound Med Biol 2012; 38:593-600. ten Kate GL, Sijbrands EJ, Valkema R, ten Cate FJ, Feinstein SB, van der Steen AF, Daemen MJ, Schinkel AF. Molecular imaging of inflammation and intraplaque vasa vasorum: A step forward to identification of vulnerable plaques? J Nucl Cardiol 2010;17:897-912.

van den Oord SCH, Akkus Z, Bosch JG, Hoogi A, ten Kate GL, Renaud G, Sijbrands EJG, Verhagen HJ, van der Lugt A, Adam D, de Jong N, van der Steen AFW, Schinkel AFL. Quantitative contrast-enhanced ultrasound of intraplaque neovascularization in patients with carotid atherosclerosis. Ultraschall Med 2015;36:154-161.

van Rooij T, Daeichin V, Skachkov I, de Jong N, Kooiman K. Targeted ultrasound contrast agents for ultrasound molecular imaging and therapy. Int J Hyperthermia 2015;31:90-106.

Winter PM, Morawski AM, Caruthers SD, Fuhrhop RW, Zhang H, Williams TA, Allen JS, Lacy EK, Robertson JD, Lanza GM, Wickline SA. Molecular imaging of angiogenesis in early-stage atherosclerosis with $\alpha \mathrm{v} \beta 3$-integrin-targeted nanoparticles. Circulation 2003;108:2270-2274.

Yan F, Li X, Jin Q, Chen J, Shandas R, Wu J, Li L, Ling T, Yang W, Chen Y, Liu X, Zheng H. Ultrasonic imaging of endothelial CD81 expression using CD81-targeted contrast agents in in vitro and in vivo studies. Ultrasound Med Biol 2012;38:670-680. 